\title{
Environmental Production of Fashion Colors from Natural Dyes
}

\author{
KHADIJAH R KASHKAR and HEBA F MANSOUR* \\ Department of Fashion Design, Faculty of Art and Design, \\ King Abdul Aziz University, Saudi Arabia \\ hebalfm@yahoo.co.uk
}

Received 21 October 2012 / Accepted 12 November 2012

\begin{abstract}
Dyeing is one of the most delightful textile arts which are an important branch in fashion design. Natural dyes is a fascinating phenomenon that enticed researchers to their chemistry and production of fantastic novel hues to explore the point that no other dyes provide a better opportunity teaching how to protect and respect the environment. In this research silk fabric was dyed by a mixture of different percentages of cochineal, turmeric and indigo powders in water-acetone co solvent to possess an ecological acceptable for dye extraction. Extraction and dyeing processes were carried out together in one step at different $\mathrm{pH}$ values using sonic energy regarding the promising technique in saving energy. Silk dyeing exhibited a variety of shades according to the evaluated colorimetric data which could be attributed to their resonating structures, where the $\mathrm{pH}$ values play important parameter in this phenomenon and control the adsorption capacity of dyes onto silk. So, this research give the chance to produce different hues from the traditional natural dyes to improve the natural dyeing cultural heritage to meet the environmental future demands technology of high quality fantastic dyed patterns through an economical point pf view.
\end{abstract}

Keywords: Natural dyes, Sonic energy, Silk, Eco-friendly dyeing

\section{Introduction}

Coloring is one of the most delightful arts and the most important branches of manufacture; before the mid- $19^{\text {th }}$ century professional dyers of fine silks and woolens had to rely on such homely substances as dried insects, roots and leaves of plants, concluding that natural dyes are an education in ecology and ethics, where no other dyes provide a better opportunity teaching how to protect and respect the environment ${ }^{1}$.

Nowadays, textile dyeing processing industry is one of the major environmental polluters; synthetic dyes have been in use globally in textile industries due to their availability, lower prices and wider ranges of bright shades with considerably improved color fastness properties in comparison with natural dyes ${ }^{2}$. But according to the application of synthetic dyes, much water effluent generated during textile dyeing would pollute the environment as it contains a heavy load of chemicals, where it is estimated that $10-15 \%$ of 
the dye is lost in the effluent during the dyeing process ${ }^{3}$. Thus, renewed international interest has arisen in natural dyes which have gained momentum due to the increased awareness of the environmental and health hazards associated with synthetic dyes ${ }^{3}$ in addition to their creative potential, excellent fastness, repeatability, softness, lustrous subtle and bright where appearance is generally regarded as the most important textile attribute for consumer acceptance and endues ${ }^{4}$.

Natural dyes are classified based on their chemical structure, sources method of application, color, etc. The most traditional natural colors representing the principle colors are the yellow turmeric, the red cochineal, and the blue indigo.

Turmeric (Curcuma longa) is a naturally occurring yellow plant belonging to the ginger family; it has been known to the east Indians for several thousand years, its rhizome is used as a dietary spice coloring agent in foods and textiles. The main pigment compound in turmeric is called curcumin as shown in Figure $1^{5}$. There are three curcuminoids, which make up 2 to $5 \%$ of the spice and are all dicinnamoylmethane derivatives ${ }^{6-9}$, I: diferuloylmethane:1,7-bis-(4-hydroxy-3-methoxyphenyl)-hepta-1,6-diene-3,5-dione (Chemical formula: $\mathrm{C}_{21} \mathrm{H}_{20} \mathrm{O}_{6}$ : CAS. number: 458-37-7, Formula weight: 368), II: p-hydroxycinnamoylferuloylmethane:1-(4-Hydroxyphenyl)-7-(4-hydroxy-3-methoxyphenyl)-hepta-1,6diene-3,5-dione (Chemical formula: $\mathrm{C}_{20} \mathrm{H}_{18} \mathrm{O}_{5}$ : C.A.S. number: 33171-16-3, Formula weight: 338) and III: p,p-dihidroxydicinnamoylmethane:1,7-bis-(4-hydroxyphenyl)-hepta-1,6-diene3,5-dione. Curcumin $\mathbf{I}$ is the main coloring curcuminoids compound, it is an orange-yellow crystalline powder "natural yellow 3" practically insoluble in water and ether but soluble in ethanol, dimethylsulfoxide, and acetone. The principal coloring components of curcumin exhibit a keto-enol tautomerism and antioxidative properties. ${ }^{8}$ It is s identified as [1, 6heptadiene-3,5-dione-1,7-bis(4-hydroxy-3-methoxyphenyl)-(1E,6E) or diferuloyl-methane $\left(\mathrm{C}_{21} \mathrm{H}_{20} \mathrm{O}_{6}\right)$; (Chemical formula: $\mathrm{C}_{19} \mathrm{H}_{16} \mathrm{O}_{4}$ : C.A.S. number: 33171-05-0, Formula weight: $308^{10,11}$.<smiles>[R]c1cc(/C=C/C(=O)CC(=O)/C=C/c2ccc(O)c([R])c2)ccc1O</smiles>
I) $\mathrm{R} 1=\mathrm{R} 2=\mathrm{OCH} 3$
II) $\mathrm{R} 1=\mathrm{OCH} 3, \mathrm{R} 2=\mathrm{H}$
III) $\mathrm{R} 1=\mathrm{R} 2=\mathrm{H}$

Figure 1. Chemical structure of curcumin

Most of natural red-color dyes have high solubility in water and act as acid dyes, which is why they bond to protein fibers ${ }^{1,12}$. Cochineal is one of the species with great economic importance, since ancient times, is the 'American cochineal' Dactylopius Coccus Costa (which some publications still refer to as Coccus cacti L.) because from the dried bodies of the adult females, where the little cochineal bug will give the most color when ground into a fine powder to obtain colors of dark burgundy to bright red to soft lilac and pink based on carmine. Carmine consists of an aluminum or calcium-aluminum lake on an aluminum hydroxide substrate of carminic acid; the coloring principle of cochineal ${ }^{13}$.

Carminic acid is a hydroxyanthraquinone with a lateral chain of $C$ - glycosyl and only one position free on the aromatic nucleus, by other words; it is an anthraquinino with other aglycones presents are kermesic acid (3,5,6,8-tetrahydroxy-1-methyl-2-anthraquinone carboxylic acid) and flavokermesic acid o laccaic acid D (3,6,8-trihydroxy-1-methyl-2anthraquinone carboxylic acid) ${ }^{14}$. The composition of carminic acid as shown in Figure 2 was proposed to be $\mathrm{C}_{22} \mathrm{H}_{20} \mathrm{O}_{13}$ and it comprises approximately $10 \%$ of cochineal and 2-4\% of its extract ${ }^{14}$. 


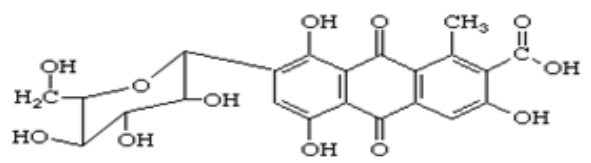

Figure 2. Chemical structure of carminic acid

It is used as brilliant red coloring agent (CAS Reg. No.: 1260-17-9; EINECS: 215-023-3; No. Shoultz: 1381; C.I.: 75470; Natural Red 4; E120). It is one of the most light and heat stable of all the colorants and is more stable than many synthetic food colors ${ }^{1}$. Carminic acid has been widely used to color foods, beverages, textiles, pharmaceuticals and cosmetics products due its relatively high chemical and biological stability and its apparent lack of mutagenic, carcinogenic or genotoxic effects. This stability and the concomitant absence of toxicity have been attributed to the presence of the $C$-Glycosyl moiety. Besides the color attributes, recently, also has been reported to beneficial to health with potential antibiotic and antitumor properties. At the beginning of the $21^{\text {st }}$. century it is predicted that many colors will be used for both their additional beneficial functions in the body, as well as, coloring effect ${ }^{14}$.

Indigo which has been used for 4000 years is described as the blue of all old textiles. It seems to be the oldest known colorant; Natural Blue 3 of Indigotin or Indican pigment as shown in Figure 3. It has been made from several different dye plants, such as Indigofera tinctoria and Indigo suffraticosa. Today, it retains its position as one of the world's most important industrial chemicals. ${ }^{15}$ It is actually used for textile dyeing and printing where small amounts are used for dyeing wool and silk. In 2009; large spills of blue dyes had been reported downstream of a blue jeans manufacturer in Lesotho. Because of its high value as a trading commodity and low oral toxicity, indigo was often referred to as Blue Gold. It is a so-called vat dye, which means that it needs to be reduced to its water soluble leuco-form before dyeing ${ }^{16}$.

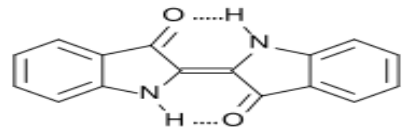

Figure 3. Chemical structure of indigo

Natural dyes are generally prepared by boiling the crushed powder with water and sometimes it is left to steep in cold water. Technology for production of natural dyes could vary from simple aqueous to complicated solvent systems to sophisticated supercritical fluid extraction techniques depending on the product and purity required ${ }^{1}$. Several researches observed that extraction of natural dyes with co-solvents induced rise to extracts incompletely soluble in water ${ }^{17,18}$.

On the other hand, the use of ultrasonic in the extraction and dyeing methods to increase the yield of colorants is being attempted and represents a promising technique in saving energy, providing effectiveness in the silk treatment, dyeing and mordanting in comparison with the conventional heating system ${ }^{19-24}$.

Previous scientific researchers were focused on the application of natural dyes on the different textile fabrics, mordants and mordanting methods, etc., recording their fastness properties and colorimetric data.

In the present paper there is an effort taking place to explore the availability of mixing turmeric, cochineal and indigo powders with different percentages to dye silk that was chosen according to its unique combination of properties to produce renewable aesthetic shades under the influence of $\mathrm{pH}$ values. This goal was assisted by water acetone co-solvent 
that possesses an ecological acceptable for dye extraction and sonic energy due to its considerable saving in processing time and chemical used. The renewable colors or shades of the dyed samples have been evaluated on computer color matching system in terms of $\mathrm{K} / \mathrm{S}$ and $\mathrm{L}^{*} \mathrm{a}^{*} \mathrm{~b} *$ color coordinates. As a result, the study will complete the economical point of view together with the aesthetic duty and environmental image.

\section{Experimental}

Degummed and bleached plain Habotain silk fabric $\left(30 \mathrm{~g} / \mathrm{m}^{2}\right)$ purchased from Sherazad Com. NZ was further treated at a liquor ratio of 50:1 with $2 \mathrm{~g} / \mathrm{L}$ Nonidet ${ }^{\circledR} \mathrm{P} 40$ Substitute (Sigma-Aldrich NZ. Ltd.), for $15 \mathrm{~min}$ at $80{ }^{\circ} \mathrm{C}$, then thoroughly rinsed and dried at ambient temperature ${ }^{12}$.

Curcumin, indigo and cochineal powders purchased from Hands Ashford Ltd Christchurch- New Zealand. Acetic acid, sodium hydroxide, sodium sodium dithionite and acetone were of laboratory reagent grade.

\section{Extraction and dyeing processes}

Curcumin and indigo powders were mixed together with percentages of $50 \%$ of each of them, and $75 \%$ curcumin with $25 \%$ indigo. Curcumin and cochineal powders were mixed together with percentages of $50 \%$ of each of them in addition to $75 \%$ curcumin with $25 \%$ cochineal. On the other hand; cochineal and indigo powders were mixed together with percentages of $50 \%$ of each of them in addition to $75 \%$ cochineal with $25 \%$ indigo and $25 \%$ cochineal with $75 \%$ indigo.

Ultrasonic assisted both the extraction and dyeing processes of the mentioned mixtures percentages in one step, using $20 \%$ (v/v) of acetone: water co-solvent at $50{ }^{\circ} \mathrm{C}$ for $1 \mathrm{~h}$ at different $\mathrm{pH}$ values of (3, 7 and 9), using a material to liquor ratio of $1: 100$. "In case of indigo dyeing $10 \mathrm{~g} / \mathrm{L}$ of sodium dithionite was added to the dye-bath".

The dyed samples were washed with $2 \mathrm{~g} / \mathrm{L}$ of each of sodium carbonat, and Nonidet ${ }^{\circledR} \mathrm{P}$ 40 Substitute at $60{ }^{\circ} \mathrm{C}$ for $30 \mathrm{~min}$. using a material to liquor ratio of $1: 50$, then were thoroughly rinsed in worm and cold water, then left to dry at ambient temperature.

\section{Measurement}

Color strength of the dyed fabric samples, in terms of the K/S values, was obtained by using the Kubelka Munk equation ${ }^{25,26}$.

$$
f(R)=\frac{(1-R)^{2}}{2 R}=\frac{k}{s}
$$

Where $K$ is the absorption coefficient and $S$ is the scattering coefficient for a colorant at a specific wavelength; $R$ is the fractional reflectance value of the dye on the substrate at the $\lambda_{\max }$. The $K / S$ value at $\lambda_{\max }$ is directly proportional to the concentration of dye on the substrate using Cary 100 UV-Vis spectrophotometer.

The CIE-Lab values of the dyeing were measured on a CM-2600d Konica MINOLTA color meter and the cylindrical co-ordinates of color were determined after exposure to irradiation from an Xe 150 watt arc lamp. The colors are given as CIE L*a*b* coordinates, as specified by the International Commission on Illumination with $\mathrm{L}^{*}$ corresponding to brightness $(100=$ white, $0=$ black), $\mathrm{a}^{*}$ to the red-green coordinate (positive sign $=$ red, negative sign $=$ green) and $\mathrm{b}^{*}$ to the yellow-blue coordinate $(\text { positive sign }=\text { yellow, negative sign }=\text { blue })^{27}$.

\section{Results and Discussion}

As shown in Figure 4; on mixing 50\% of each of turmeric and indigo together, wave lengths of two colors were observed, representing the yellow color at $\lambda_{\max } 423,424$ and the bluish 
green color at $\lambda_{\max } 583-586$. For the yellow, the maximum color strength was achieved in the neutral medium, while for the bluish green; the maximum color strength value was achieved in the alkaline medium.

As shown in Figure 5; on mixing 75\% turmeric with 25\% indigo, wave lengths of two colors were observed, representing the yellow color at $\lambda_{\max } 416-453$ and the bluish green at $\lambda_{\max } 556-588$. For the yellow color, the maximum color strength was achieved in the neutral medium, on the other hand the samples exhibited the yellow color in the three mediums, while for the bluish green color, and the maximum color strength value was achieved in both the acidic and neutral mediums.

As shown in Figures $(4 \& 5) \mathrm{C}$; the $\mathrm{pH}$ values of the dye bath have considerable effect on the color co-ordinate values. The lightness $\mathrm{L}^{*}$ values increase in the acidic and alkaline mediums and then these values were decreased when adjusting the $\mathrm{pH}$ of dye bath in the neutral medium. This observation relevant to lightness could be attributed with change in increase and decrease of color strength (\%) values with change in the $\mathrm{pH}$ of the dye bath. The tone of the samples at various $\mathrm{pH}$ of dye bath is less greener and more yellowier in the acidic and neutral medium as indicated by the values of $a^{*}$ and $b^{*}$ These changes could be attributed with its resonating structures ${ }^{28}$.
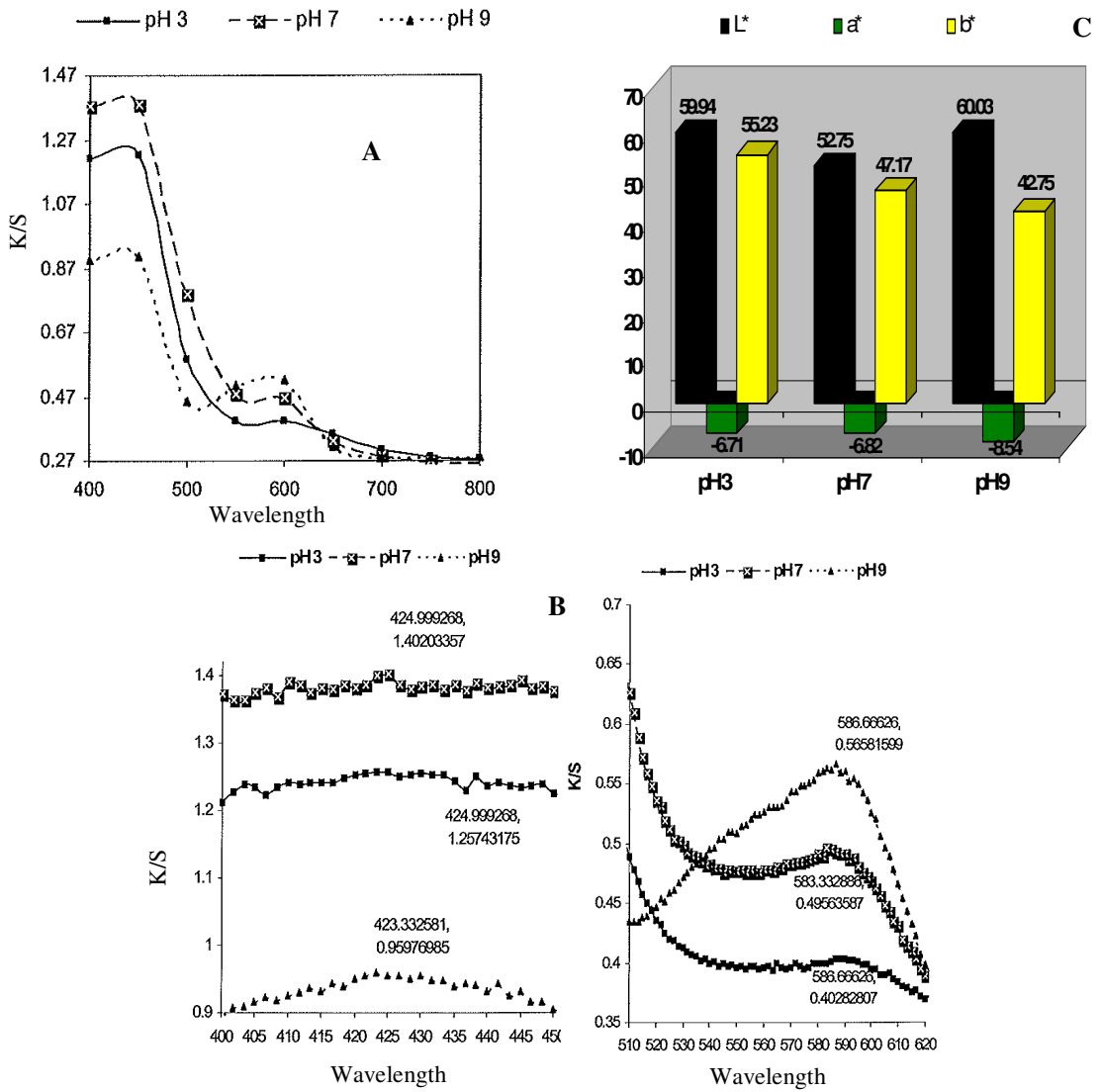

Figure 4. A) Effect of $\mathrm{pH}$ values on wave length and $\mathrm{K} / \mathrm{S}$ of silk dyed with an extract composed of a mixture of $50 \%$ turmeric with $50 \%$ indigo; B) Identification of the highest wave lengths and $\mathrm{K} / \mathrm{S}$ values according to Figure $4 \mathrm{~A}$; C) Effect of $\mathrm{pH}$ values on the CIE-Lab values of silk dyed with $50 \%$ curcumin and $50 \%$ indigo extract at different $\mathrm{pH}$ values 

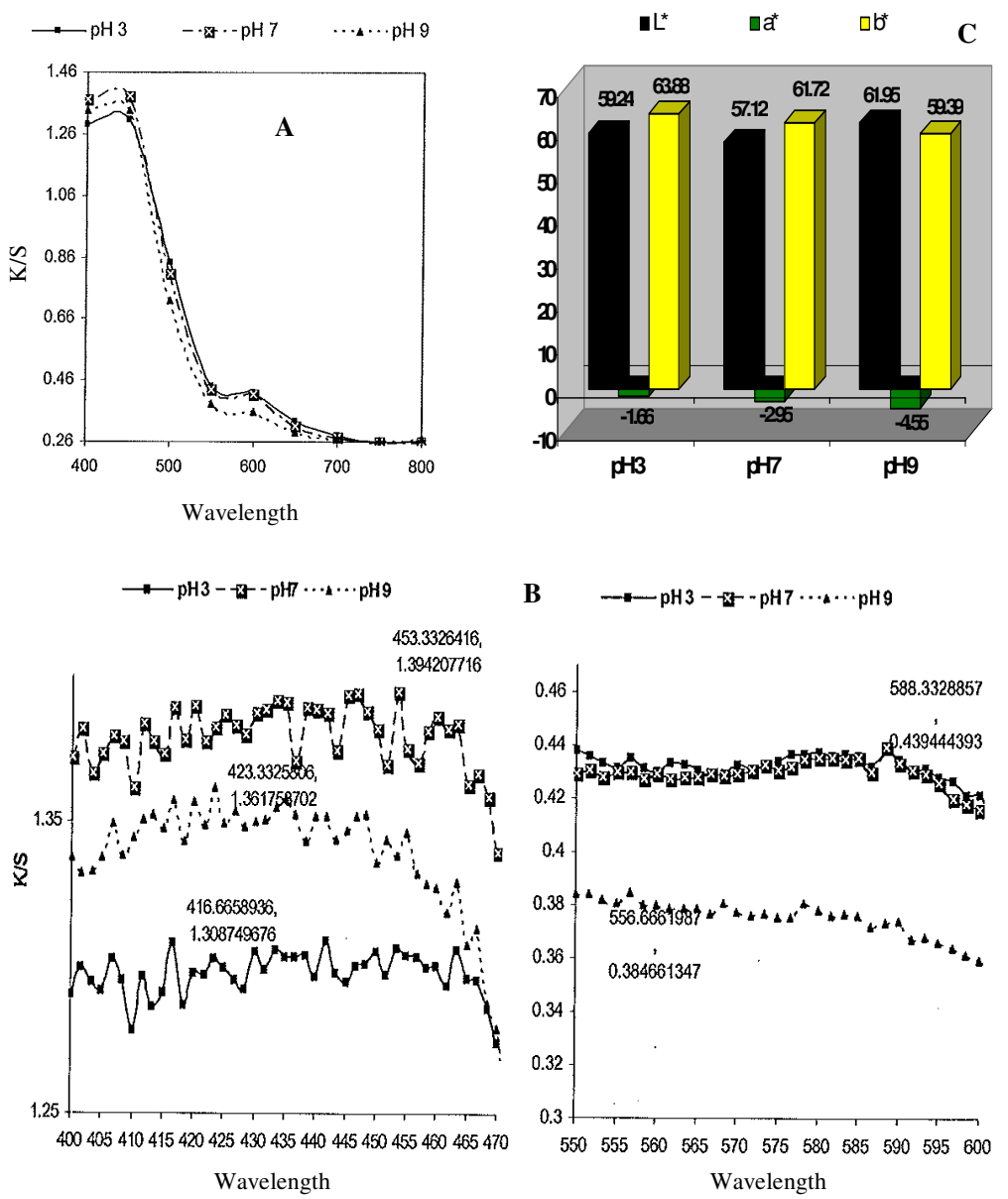

B $\quad \rightarrow-\mathrm{pH}_{3}--\mathrm{x}-\mathrm{pH} 7 \cdots \ldots \mathrm{pH} 9$

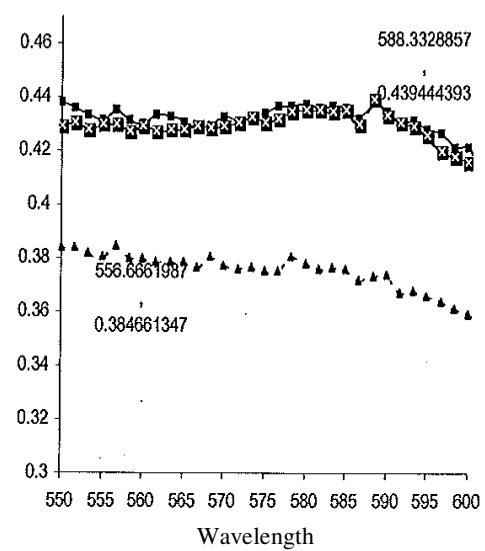

Figure 5. A) effect of $\mathrm{pH}$ values on wave length and $\mathrm{K} / \mathrm{S}$ of silk dyed with an extract composed of a mixture of $75 \%$ turmeric with $25 \%$ indigo; B) Identification of the highest wave lengths and $\mathrm{K} / \mathrm{S}$ values according to Figure $5 \mathrm{~A}$; C) Effect of $\mathrm{pH}$ values on the CIE-Lab values of silk dyed with $75 \%$ curcumin and $25 \%$ indigo extract at different $\mathrm{pH}$

As shown in Figure 6; on mixing 50\% of each of turmeric and cochineal together, wave lengths of two colors were observed, representing the yellow color at $\lambda_{\max } 419,426,446$ and the violet one at $\lambda_{\max } 556-569$, where the maximum color strength values of the two colors were achieved in the acidic medium'.

As shown in Figure 7; on mixing $75 \%$ curcumin with $25 \%$ cochineal, wave lengths of two colors were observed, representing the yellow color at $\lambda_{\max } 419,423,444$ and the violet one at $\lambda_{\max } 568$, where the maximum color strength values of the two colors were achieved in the acidic medium.

As shown in Figures $(6 \& 7) \mathrm{C}$; the $\mathrm{L}^{*}$ (lightness or brightness) has its maximum value at $\mathrm{pH} 9$ in comparison with the other mediums in investigation which reflects the suitability of alkaline medium for obtaining bright color from the two dyes used. The $\mathrm{a}^{*}$ and $\mathrm{b}^{*}$ values have positive signs, reflecting the red color of cochineal and the yellow color of 
curcumin respectively, reaching their maximum content at $\mathrm{pH}$ 3. Since cochineal dye is characterized by producing colors of dark burgundy to bright red to soft lilac and pink based on carmine ${ }^{14}$, it was recorded that silk samples dyed with mixtures of i: $50 \%$ of each of curcumin and cochineal, ii: 75 curcumin with 25 cochineal exhibited a greenish yellow color in the acidic medium, yellow color in the alkaline medium and yellowish orange color in the neutral medium with much yellowier color in case of $75 \%$ curcumin with $25 \%$ cochineal.
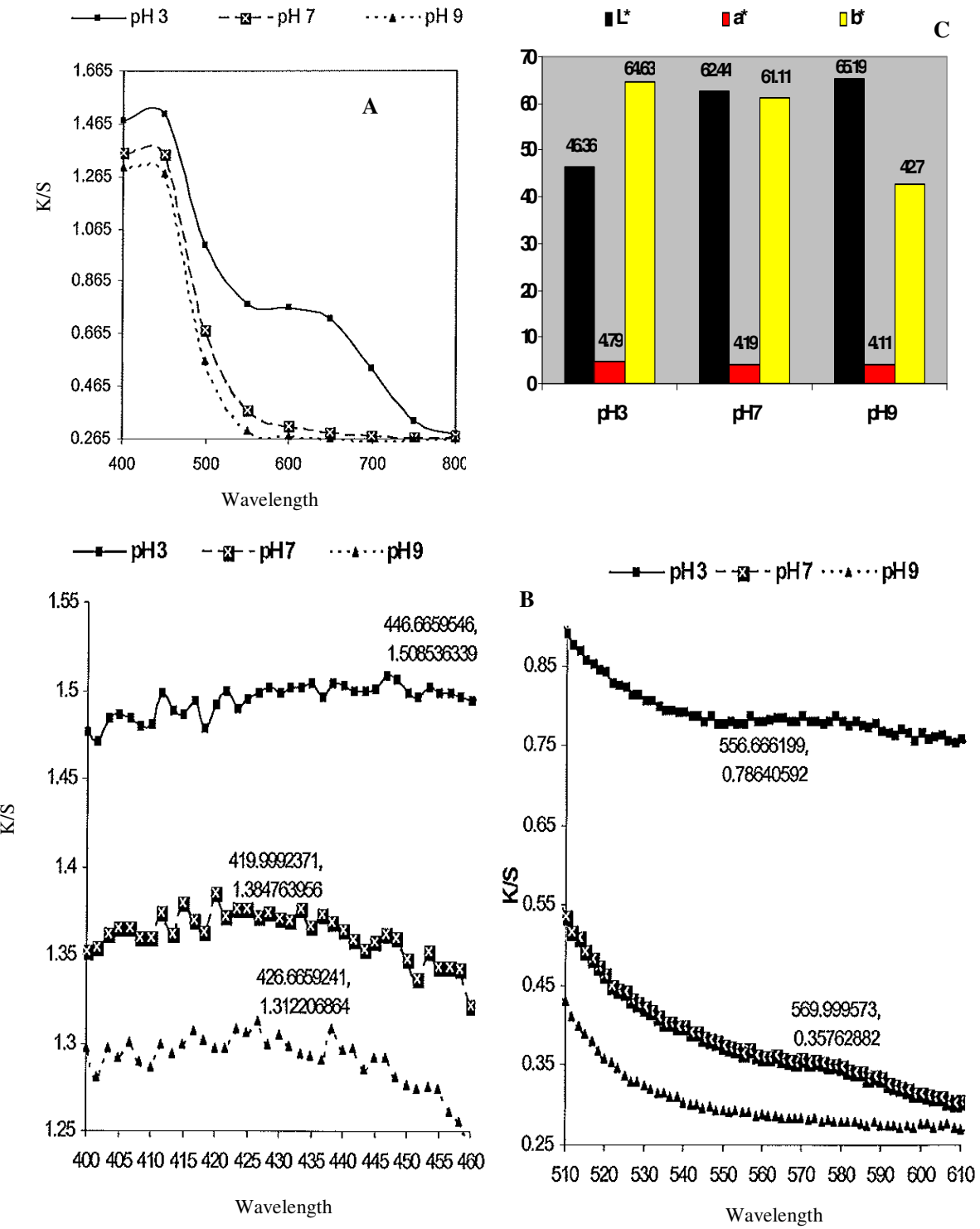

Figure 6. A) Effect of $\mathrm{pH}$ values on wave length and $\mathrm{K} / \mathrm{S}$ of silk dyed with an extract composed of a mixture of $50 \%$ curcumin with $50 \%$ cochineal; B) Identification of the highest wave lengths and K/S values according to Figure 6A; C) Effect of $\mathrm{pH}$ values on the CIE-Lab values of silk dyed with $50 \%$ curcumin and $50 \%$ cochineal extract at different $\mathrm{pH}$ values 

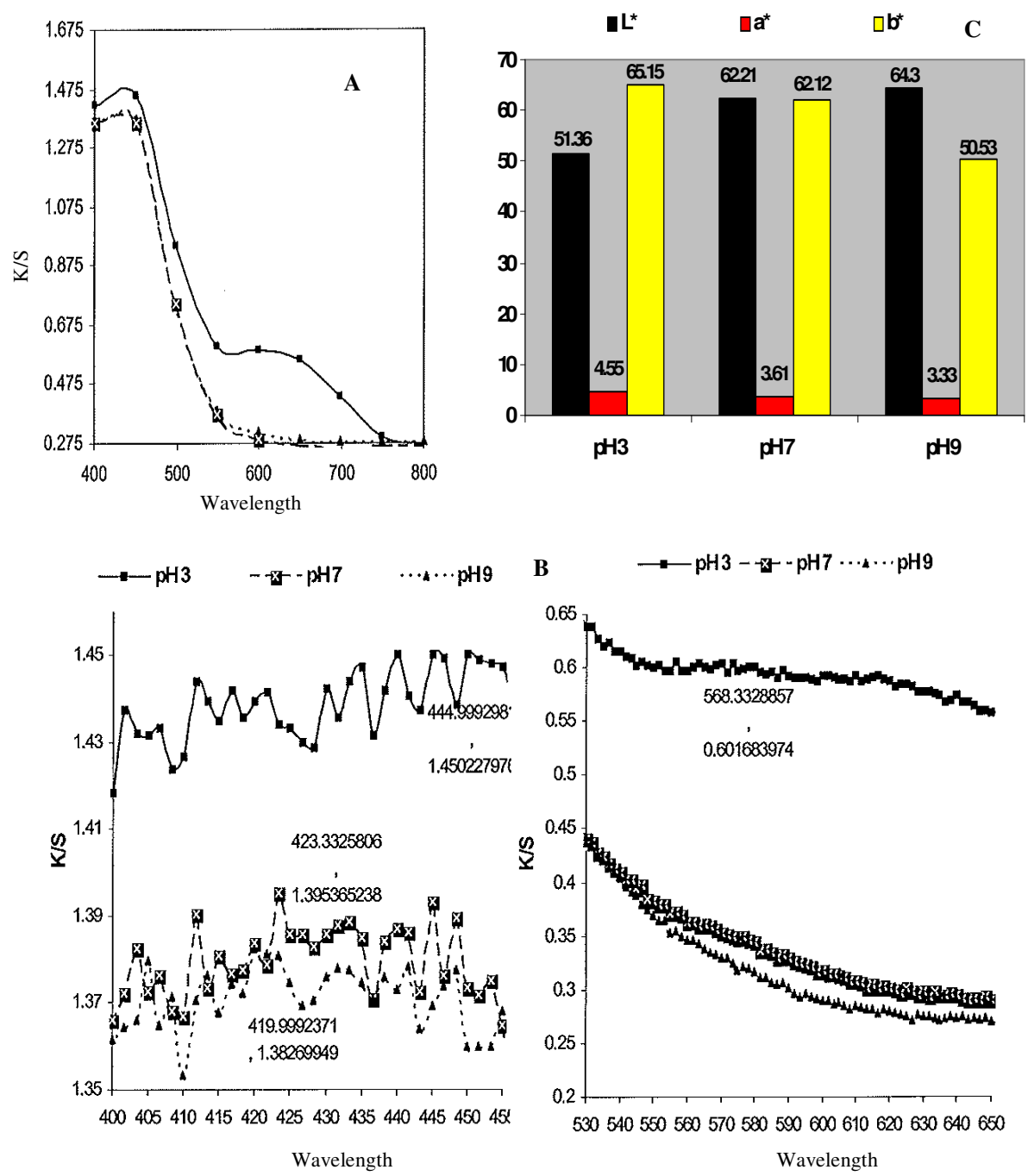

Figure 7. A) Effect of $\mathrm{pH}$ values on wave length and $\mathrm{K} / \mathrm{S}$ of silk dyed with an extract composed of a mixture of $75 \%$ curcumin with $25 \%$ cochineal; B) Identification of the highest wave lengths and $\mathrm{K} / \mathrm{S}$ values according to Figure 7A; C) Effect of $\mathrm{pH}$ values on the CIE-Lab values of silk dyed with $75 \%$ curcumin and $25 \%$ cochineal extract at different $\mathrm{pH}$ value

As shown in Figure 8; on mixing 75\% cochineal with 25\% indigo, wave lengths of two colors were observed, representing red color in the acidic medium,to violet color in the neutral and alkaline mediums at $\lambda_{\max } 521,558$ and 581 respectively. The maximum color strength value was achieved in the alkaline medium. The L* (lightness or brightness) has its maximum value at $\mathrm{pH} 7$ in comparison with the other mediums in investigation which reflects the suitability of neutral medium for obtaining bright color from the two dyes. The $a^{*}$ values have positive signs, reflecting the red color of cochineal which achieve its maximum content at $\mathrm{pH} 3$. The $\mathrm{b}^{*}$ values have negative signs reflecting the blue color of indigo which achieve its maximum value at $\mathrm{pH} 9$. 

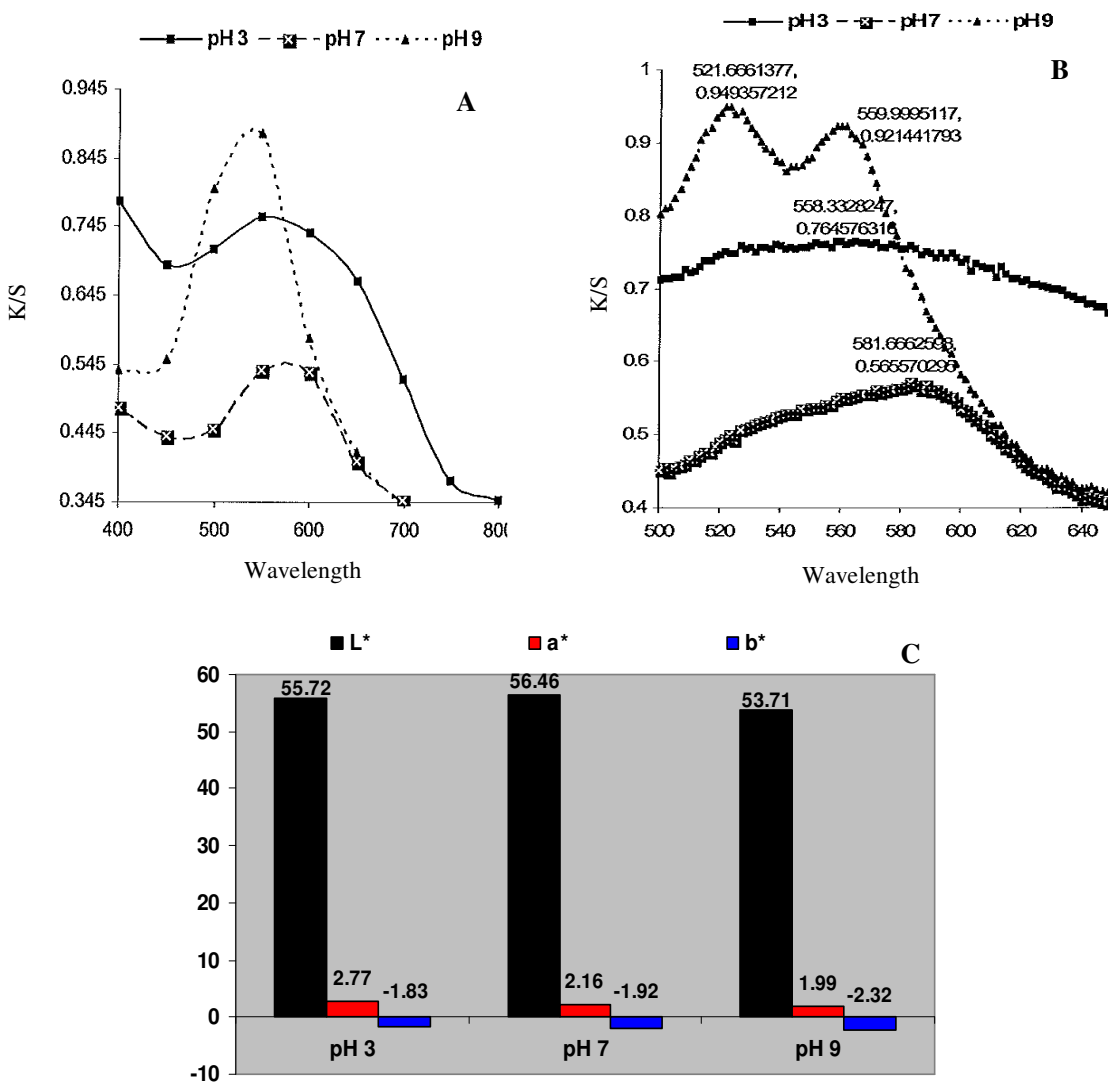

Figure 8. A) Effect of $\mathrm{pH}$ values on wave length and $\mathrm{K} / \mathrm{S}$ of silk dyed with an extract composed of a mixture of $75 \%$ cochineal with $25 \%$ indigo; B) Identification of the highest wave lengths and $\mathrm{K} / \mathrm{S}$ values according to Figure $8 \mathrm{~A}$; C) Effect of $\mathrm{pH}$ values on the CIE-Lab values of silk dyed with $50 \%$ cochineal and $50 \%$ indigo extract at different $\mathrm{pH}$ values

As shown in Figure 9; on mixing 50\% cochineal with 50\% indigo, a violet color was observed at $\lambda_{\max }$ [568, 589 and 581] $\mathrm{nm}$ in the acidic, neutral and alkaline mediums respectively. The maximum color strength value was achieved in the acidic medium. The $\mathrm{L}^{*}$ (lightness or brightness) has its maximum value at $\mathrm{pH} 7$ in comparison with the other mediums in investigation which reflects the suitability of neutral medium for obtaining bright color from the two dyes. The $\mathrm{a}^{*}$ values have positive signs, reflecting the red color of cochineal which achieve its maximum content at $\mathrm{pH} 3$. The $\mathrm{b}^{*}$ values have negative signs reflecting the blue color of indigo which achieve its maximum value at $\mathrm{pH} 9$.

As shown in Figure 10; on mixing $25 \%$ cochineal with $75 \%$ indigo, a violet color was observed at $\lambda_{\max } 574 \mathrm{~nm}$ in the neutral medium and $571 \mathrm{~nm}$ in the alkaline and acidic mediums. The maximum color strength value was achieved in the neutral medium. The $\mathrm{L}^{*}$ (lightness or brightness) has its maximum value at $\mathrm{pH} 3$ in comparison with the other mediums in investigation which reflects the suitability of acidic medium for obtaining bright color from the applied two dyes. The $\mathrm{a}^{*}$ values have positive signs, reflecting the red color of cochineal which achieve its maximum content at $\mathrm{pH} 3$. The $\mathrm{b}^{*}$ values have negative signs reflecting the blue color of indigo which achieve its maximum value at $\mathrm{pH} 9$. 

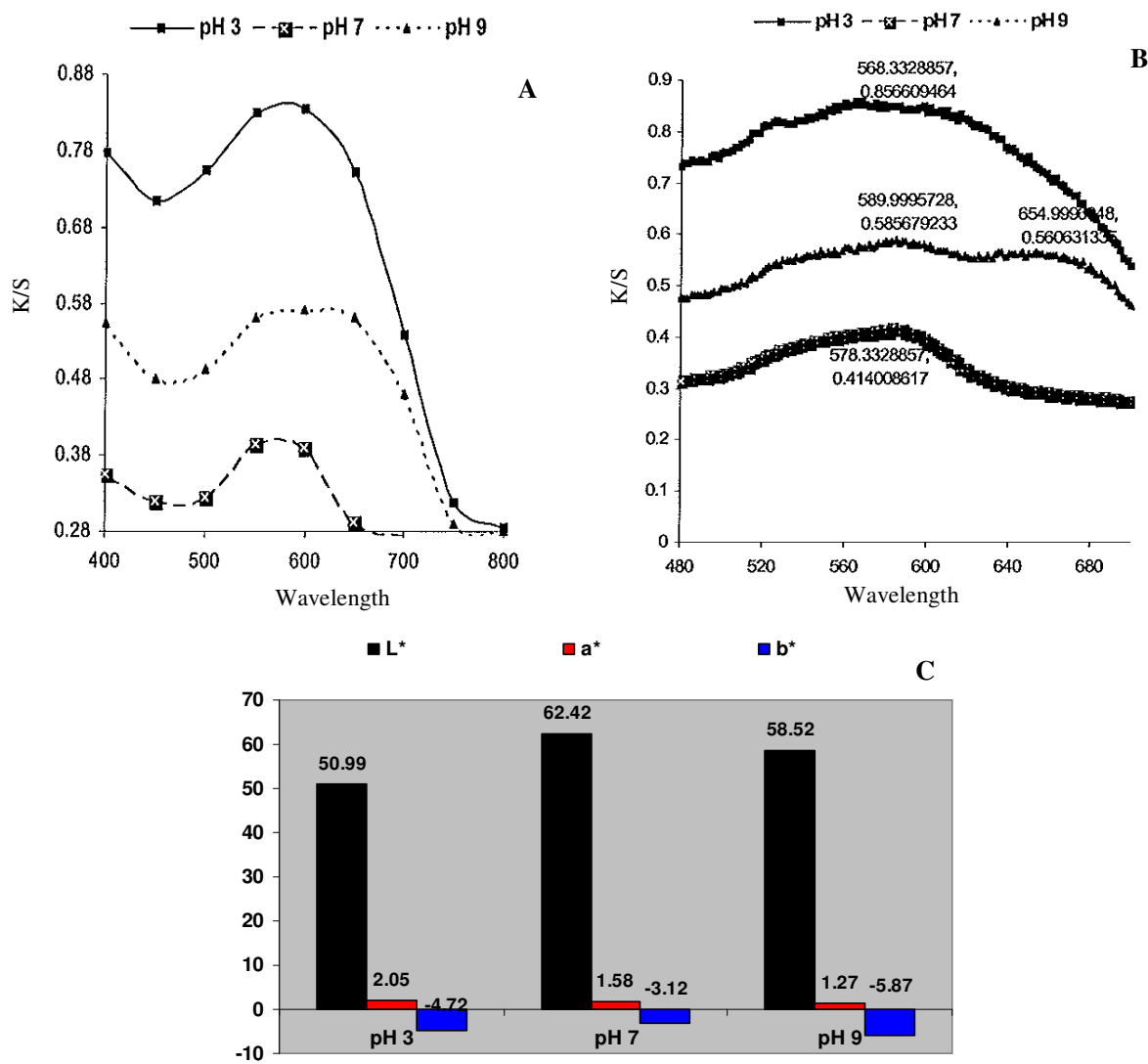

Figure 9. A) Effect of $\mathrm{pH}$ values on wave length and $\mathrm{K} / \mathrm{S}$ of silk dyed with an extract composed of a mixture of $50 \%$ cochineal with $50 \%$ indigo; B) Identification of the highest wave lengths and K/S values according to Figure 9A; C) Effect of $\mathrm{pH}$ values on the CIE-Lab values of silk dyed with $25 \%$ cochineal and $75 \%$ indigo extract at different $\mathrm{pH}$ values

$\rightarrow-\mathrm{pH} 3-\mathrm{-}-\mathrm{pH} 7 \ldots \ldots \mathrm{pH} 9$

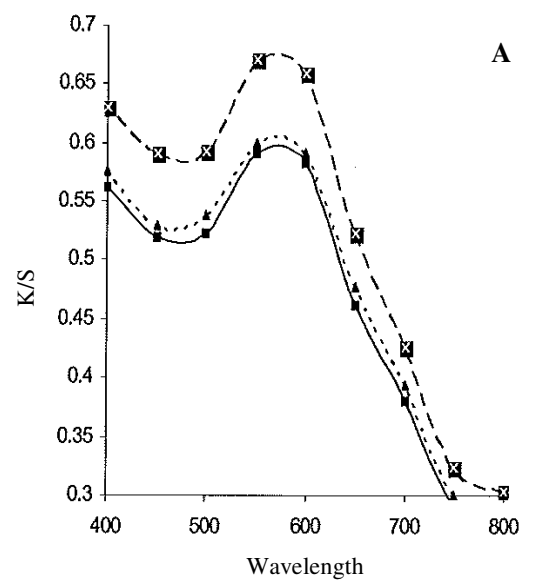

$\rightarrow-\mathrm{pH} 3-\overline{-\mathrm{x}}-\mathrm{pH}+\cdots \cdots \mathrm{pH}$

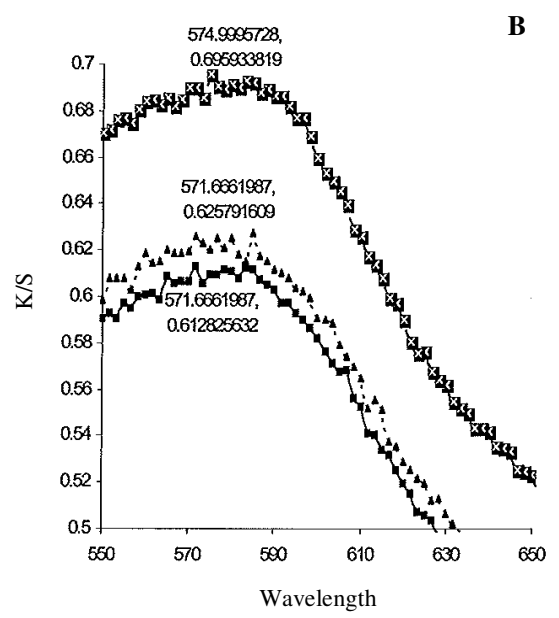




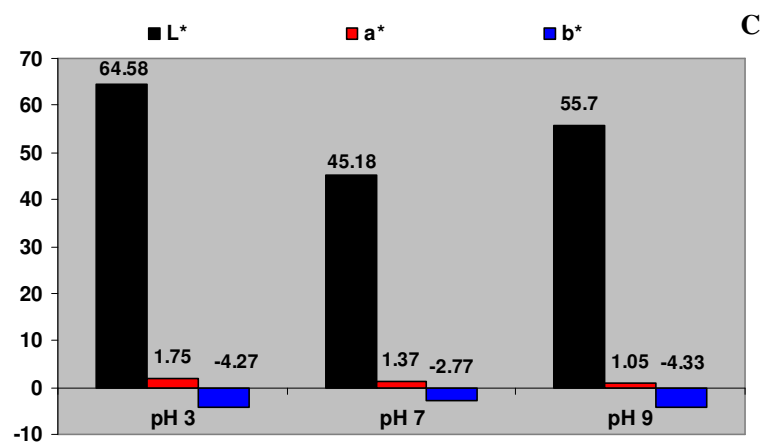

Figure 10. A) effect of $\mathrm{pH}$ values on wave length and $\mathrm{K} / \mathrm{S}$ of silk dyed with an extract composed of a mixture of $25 \%$ cochineal with $75 \%$ indigo; B) Identification of the highest wave lengths and $\mathrm{K} / \mathrm{S}$ values according to Figure $10 \mathrm{~A}$; C) Effect of $\mathrm{pH}$ values on the CIELab values of silk dyed with $75 \%$ cochineal and $25 \%$ indigo extract at different $\mathrm{pH}$ values

The $\mathrm{pH}$ of the dye solution is one of the most important parameters controlling the adsorption capacity of dye onto silk ${ }^{29,30}$. The effect of $\mathrm{pH}$ on the spectroscopy studies of the mixtures of turmeric and indigo onto silk were evaluated in Figures 1 and 2. Results indicated that the maximum color strength values were clearly achieved at acidic medium.

From the Greek from Greek chromophorus (chromos color), a chromophore is generally a groups of atoms in a molecule responsible for the interaction with the radiation at certain wavelength; example of common chromophore is conjugated multiple bond, rich in electrons, where the energy of the light which passes through the sample is absorbed by some electrons and they are in that way "excited" to a higher energetic level (state).

UV/Visible spectrums of pure curcumin in distilled water showed two well defined $\lambda_{\max }$ at $259 \mathrm{~nm}$ and $405 \mathrm{~nm}$, but it absorbs maximally at 415 to $420 \mathrm{~nm}$ in acetone ${ }^{31}$. The similar $\lambda_{\max }$ were obtained in the spectra of curcumin obtained through extraction from turmeric rhizomes \& through dyed fabric in acetone /water solution as well. The presence of the two $\mathrm{C}=\mathrm{O}$ groups seems to suggest that the $405 \mathrm{~nm}$ in the visible region is due to the $\mathrm{n}-\pi *$ transition of conjugated chromophore. The $\lambda_{\max }$ at 259 is due to the $\pi-\pi *$ transition that is attributed to alternate double bonds present in the curcumin.

Curcumin is an oil-soluble pigment, practically insoluble in water at acidic and neutral $\mathrm{pH}$, and soluble in alkali. In solutions the principal coloring components of curcumin exhibit keto-enol tautomerism and depending on the solvent, up to 95 percent are in the enol form ${ }^{31}$. It has a brilliant yellow hue at $\mathrm{pH} 2.5$ to 7 and takes on a red hue at $\mathrm{pH}>7$ and its decomposition was $\mathrm{pH}$ dependent and occurred faster at neutral to basic conditions ${ }^{32}$. At $\mathrm{pH}<1$, aqueous solutions of diferuloylmethane have a red color which indicates the protonated form (H4A+). In the $\mathrm{pH}$ range 1-7, the majority of diferuloylmethane species are in the neutral form (H3A). Water solubility is very low in $\mathrm{pH}$ range 1-7 and solutions are yellow. At $\mathrm{pH}>7.5$ the color changes to red. The UV visible spectral data of curcumin reveals two peaks, one in the visible region $\lambda_{\max }(420 \mathrm{~nm}, \log E=4.77)$ and the othe, $\lambda_{\max }=(265 \mathrm{~nm}$ with $\log E=4.18)$. The absorption peak in the visible region $\left(\lambda_{\max }=420 \mathrm{~nm}\right)$ explains the yellow color of the dye. On the other hand the UV visible spectral data of indigo reveals $580 \mathrm{~nm}^{31}$.

As stated before, since cochineal dye is characterized by producing colors of dark burgundy to bright red to soft lilac and pink based on carmine ${ }^{14}$, it was recorded that the silk samples dyed with mixtures of; i) $75 \%$ cochineal with $25 \%$ indigo exhibited violet color in the three mediums, ii) $50 \%$ of each of cochineal and indigo exhibited violet color in the 
alkaline and neutral medium, while grayish blue in the acidic medium and iii) $25 \%$ cochineal with $75 \%$ indigo exhibited violet color in the neutral medium while grayish blue in the acidic and alkaline mediums. From the mentioned results, mixtures of dyes exhibited different colors or shades according to $\mathrm{a}^{*}$ and $\mathrm{b}^{*}$ values which could be attributed with their resonating structures ${ }^{33}$.

Indigo is a vat dye, soluble in alkaline medium but in acidic medium its solubility will be in the least amount. Curcumin acts as direct dye, while cochineal acts as acidic one. The acidic medium is suitable for curcumin and cochineal, but not suitable for indigo. Therefore, the yellow and red color of curcumin and cochineal reached their maximum values in the acidic medium. While the blue color of indigo reached its highest values in the alkaline medium.

The $\mathrm{pH}$ of the dye solution is one of the most important parameters controlling the adsorption capacity of dyes onto silk ${ }^{28,29}$. For curcumin and cochineal dyes; the possible mechanisms for the effect of $\mathrm{pH}$ on adsorption of dyes are likely to be ionic interactions of the dye anions with the protonated amino groups on the silk fiber. The effect of dye bath $\mathrm{pH}$ can be attributed to the correlation between dye structure and silk fibers. Since the dye used is a water-soluble dye containing carboxyl groups, it would interact ionically with the protonated terminal amino groups of silk fibers at acidic $\mathrm{pH}$ via ion exchange reaction. The anion of the dye has a complex character, and when it is bound on fiber, further kinds of interactions take place together with ionic forces. This ionic attraction would increase the dyeability of the fiber. At $\mathrm{pH}>3$, however, the ionic interaction between the carboxylate anion of the dye and silk fibers decreases due to the decreasing number of protonated terminal amino groups of silk and thus lowering its dyeability.

It is to be mentioned that the lower dyeability at $\mathrm{pH}>3$ may be attributed to the enhanced desorption of the dye as its ionic bond is getting decreased ${ }^{34}$. In case of indigo dye, different forms of indigo existed in solution, each one having a different substantivity for the fiber. The non-ionic form had the highest, whilst the ionic ones had relatively less substantivity. Silk fibers could best be dyed in the acidic to slightly alkaline $\mathrm{pH}$ range. The Chemistry of the dye-bath and fiber were considered, in order to explain the effect of $\mathrm{pH}$ on color strength. Hydrogen bonding and ionic interactions seemed to be the main reason for the exhaustion of dye onto silk fiber, where hydrogen bonding occurred between the hydroxyl groups and amide groups, while ionic interactions worked at low $\mathrm{pH}$ values between the ionized and end-amino groups of the dye and fiber respectively ${ }^{29}$.

On the other hand ultrasonic represented a promising technique in saving energy by providing additional energy, which was generally attributed to the cavitation phenomenon in a liquid medium, in addition to other mechanical effects; i.e. dispersion, degassing, diffusion, and the Intense agitation of the liquid. This phenomenon led to lowering the temperature and reducing the time needed for the extraction, and the dyeing processes ${ }^{19-24}$. By the way extraction with acetone: water co-solvent includes the dipole moment, dielectric constant and refractive index values. The solvent polarity can change the position of the absorption or emission band of molecules by solvating a solute molecule or any other molecular species introduced into the solvent matrix ${ }^{17,35}$.

\section{Conclusion}

Color is one of the most fascinating phenomena which were enticed to chemistry as is well known, full comprehension compound needs knowledge of quantum chemistry and spectroscopy. To encourage the production of eco-friendly aesthetic future demands of renewable shades or colors regarding the environmental awareness towards eco-friendly 
dyeing and energy save, this article deals on the efficiency of sonic energy in assisting one step extraction and dyeing processes of silk fabric with mixtures of the traditional natural dyes; turmeric, cochineal and indigo powders with different percentages at different $\mathrm{pH}$ values in water acetone co-solvent.

It was concluded that the color values with respect to $K / S$, and $\mathrm{L}^{*} \mathrm{a}^{*} \mathrm{~b}^{*}$ values were found to be influenced by the $\mathrm{pH}$ values of the dyeing bath with respect to the chemical structure of the used dyes, where a broad variation in shade and color depth was achieved by applying mixtures of these dyes in various combinations, given that both ultrasonic and water acetone co-solvent are environmentally and ecological acceptable for dyeing technology.

\section{References}

1. $\quad$ Siva R, Current Science, 2007, 92(7), 916-919.

2. El-Nagar K, Sanad S H, Mohamed A S and Ramadan A, Polym- Plast Technol Eng., 2005, 44(7),1269-1279.

3. Iqbal J M and Ashiq M N, J Hazard Mater., 2007, 139(1), 57-66.

4. Osman E M, El-Ebissy A A and Michael M N, Res J Textile \& Apparel, 2009, 13(2), 61-68.

5. Ferreira E S B, Alison N H, McNab H and Quye A, Chem Soc Rev., 2004, 33, 329-336.

6. Balasubramanian K, Int J Quantum Chem Energy, 1990, XXXVII, 449-464.

7. Julie Jurenka S, Alternative Medicine Review, 2009, 14(2), 141-153.

8. Dalapathi Gugulothu B and Vandana Patravale B, Pharmaceut Anal Acta, 2012, 3(4), DOI: $10.4172 / 2153-2435.1000157$.

9. Jayaprakasha G K, Rao L I M and Sakariah K.K, Trends Food Sci Tech., 2005, 16(12), 533-548.

10. Jiang H, Timmermann B N and Gang D R, J Chromatogr A, 2006, 1111(1), 21-31.

11. Aggarwal B B, Kumar A and Bharti A C, Anticancer Res., 2003, 23(1A), 363-398.

12. Kongkachuichaya P, Shitangkoonb A and Chinwongamorna N, Sci Asia., 2002, 28, 161-166.

13. Marmion D M, Foods, Drugs, Cosmetics and Medical Devices, $3^{\text {rd }}$ Edn., John Wiley \& Sons, New York, 1991.

14. Allevi P, Mario Anastasia, Steve Bingham, Pierangela Ciuffreda, Alberto Fiecchi, Giuliana Cighetti, Max Muir, Antonio Scala and Tyman A, J Chem Soc Perkin Trans 1., 1998, 575-582.

15. Roessler A and Jin X, Dyes and Pigments, 2003, 59(3), 223-235.

16. Roessler A and Crettenand D, Dyes and Pigments, 2004, 63(1), 29-37.

17. Kulkarni S S, Gokhale A V, Bodake U M and Pathade G R, Universal Journal of Environmental Research and Technology, 2011, 1(2), 135-139.

18. Zin Mar W and Moe Moe S, World Academy of Science, Engineering and Technology, 2008, 2, 536-540.

19. Heba M, Clean Tech \& Environ Policy, 2009, 12(5), 571-578, DOI: 10.1007/s10098009-0267-7

20. HebaMansour F and Heffernan S, Clean Tech Environ Policy, 2011, 13(1), 207-213. DOI: 10.1007/s10098-010-0296-2

21. Kamel M M, El-Shishtawy R M, Youssef B M and Mashaly H, Dyes and Pigments. 2007, 73(3), 279-284.

22. Vajnhandl S and Le Marechal M A, Dyes and Pigments, 2005, 65, 89-101. 
23. Padma V S, Shanker R, Mahanta D and Tiwari S C, Dyes and Pigments, 2006, 76(1), 207-212.

24. Heba F M and Heffernan S, Clean Techn Environ Policy, DOI: 10.1007/s10098-0100296-2, 2010.

25. Kubelka P, JOSA, 1948, 38, 448-457.

26. Garland C E, Color Technology In Textile Chemistry, AATCC, In Gultekin C, (Ed),, 1993, 107.

27. Bechtold T, Turcanu A, Ganglberger E and Geissler S, J Clea Prod., 2003, 11, 499-509.

28. Moeyes M, Natural Dyeing in Thailand, 1993, White Lotus, Bangkok, 1993.

29. Christie R M, Mather R R and Wardman R H, The Chemistry of Color Application, Blackwell Science, Oxford, 2000.

30. Wang Y J, Pan M H, Lin A L, Ho L I, Hsieh Y S and Lin J K, J Pharm Biomed Anal., 1997, 15(12), 1867-1876.

31. Ferenc Z, Zsolt B and Miklos S, Tetrahedron: Asymmetry, 2003, 14, 2433-2444.

32. Montazer M and Parvinzadeh M, Coloration Technology, 2004, 120(4), 161-166.

33. Andrew F, Resonance, 2010, 850-855.

34. Muhammed A R, Soliman A A and Khattab M, Chem Central J., 2008, 2, 19. 